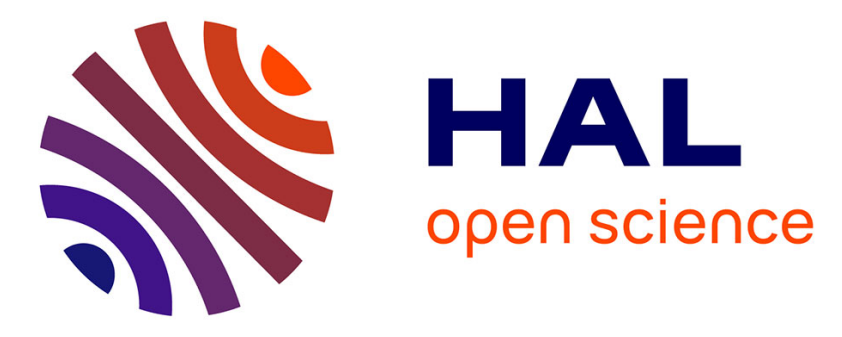

\title{
Cytokine response following perturbation of the cervicovaginal milieu during HPV genital infection
}

\author{
Christian Selinger, Massilva Rahmoun, Carmen Lia Murall, Claire Bernat, \\ Vanina Boué, Marine Bonneau, Christelle Graf, Sophie Grasset, Soraya Groc, \\ Jacques Reynes, et al.
}

\section{To cite this version:}

Christian Selinger, Massilva Rahmoun, Carmen Lia Murall, Claire Bernat, Vanina Boué, et al.. Cytokine response following perturbation of the cervicovaginal milieu during HPV genital infection. Immunologic Research, 2021, 69 (3), pp.255-263. 10.1007/s12026-021-09196-2 . hal-03354891

\section{HAL Id: hal-03354891 https://hal.science/hal-03354891}

Submitted on 26 Sep 2021

HAL is a multi-disciplinary open access archive for the deposit and dissemination of scientific research documents, whether they are published or not. The documents may come from teaching and research institutions in France or abroad, or from public or private research centers.
L'archive ouverte pluridisciplinaire HAL, est destinée au dépôt et à la diffusion de documents scientifiques de niveau recherche, publiés ou non, émanant des établissements d'enseignement et de recherche français ou étrangers, des laboratoires publics ou privés. 


\section{Title:}

Cytokine response following perturbation of the cervicovaginal milieu during HPV genital infection

\section{Authors and affiliations:}

Christian Selinger* (1), Massilva Rahmoun* (1), Carmen Lia Murall (1), Claire Bernat (1), Vanina Boué

(1), Marine Bonneau (2), Christelle Graf (2), Sophie Grasset (1), Soraya Groc (1), Jacques Reynes (3),

Christophe Hirtz (4), Nathalie Jacobs (5), Samuel Alizon (1)

*contributed equally

10

(1) Laboratoire MIVEGEC (UMR CNRS 5290, IRD 224, UM), Montpellier, France

(2) Department of Obstetrics and Gynaecology, Centre Hospitalier Universitaire de Montpellier, University of Montpellier, France

(3) Department of Infectious and Tropical Diseases, Centre Hospitalier Universitaire de Montpellier,

15 Montpellier, France

(4) IRMB-PPC, INM, Univ Montpellier, CHU Montpellier, INSERM CNRS, Montpellier, France

(5) Laboratory of Cellular and Molecular Immunology, GIGA Research, University of Liège, 4000 Liège, Belgium.

20 | Correspondence to:

Christian Selinger

Institut de Recherche pour le Développement

911 Avenue Agropolis

BP 64501

2534394 Montpellier cedex 5 - FRANCE

(+33) 448191866

christian.selinger@ird.fr 


\section{Abstract}

Human papillomaviruses (HPVs) are oncogenic viruses causing most cervical cancers. Highly prevalent in young, sexually active women, only a minority of HPV infections persist. To better characterize the immuno-modulatory impact of early HPV infections, we measured changes in a panel of 20 cytokines in cervicovaginal samples collected from young women who were tested for HPV and self-reported

35 for genital inflammation and infection symptoms.

Multi-factor statistical analyses revealed that increased IL-1Alpha and IL-12/IL-23p40 concentrations were associated with HPV infection, and that macrophage inflammatory proteins were associated in particular with high-risk HPV infections.

\section{Keywords}

Human Papillomavirus; cytokines; natural history; mucosal immunity 


\section{Introduction}

45 Human papillomaviruses (HPVs) are the most oncogenic viruses known to human, causing nearly all cervical cancers worldwide, as well as a significant fraction of other anogenital and oropharyngeal cancers.[1] Even though a majority of sexually active women acquire a genital HPV infection, most cervical HPV infections will be cleared by the immune system within 3 years[2,3] or lead to asymptomatic infections. The major risk factor for the development of high-grade cervical lesions and

50 cervical cancer is the persistence of high-risk (HR) HPV type infection.[4] Numerous studies on the HPV life cycle and pathogenesis show a broad spectrum of immune evasion strategies the virus uses to survive in its host.[5]

HPVs target the keratinocytes in the female genital tract and follow the differentiation program of these cells from the para-basal cells until the upper epithelial layers where virions are released. In

55 these layers, immune cells have limited access, thereby facilitating virus immune escape. The cervicovaginal mucosa is known to perform a pivotal role in the defense against infectious and inflammatory processes thanks to an interplay between hormones, resident microbiota, epithelial, and immune cells. In particular, cervical keratinocytes express several toll-like receptors (TLRs) that recognize pathogen-associated molecular patterns and initiate innate and adaptive immune

60 responses.[6] However, given their slow replication cycle, HPVs are capable of maintaining low expression levels of viral proteins. They can also alter host gene expression (such as chemokines, adhesion molecules, and TLRs) or impair protein function and trafficking by dysregulating keratinocyte interferon (IFN) response and other antiviral pathways.[7-9] Additionally, interference with antigen processing in HPV infections has been described and can contribute to impeding detection of infected

65 keratinocytes by cytotoxic T cells.[10]

Most HPVs studies focus on chronic infections and cancer and there is a pronounced lack of data for non-persistent (also called "incident") infections.[11] The goal of this study is to analyze the cytokinemediated response to HPV genital infections in healthy young women and describe the interplay, if any, between local cytokine secretion, HPV infection, and, more generally, infection-related 70 perturbations to the cervicovaginal milieu.

The data originates from the PAPCLEAR clinical study[12], which follows a population of sexually active, 18 to 25 --year--old women. We study a large panel of 20 soluble cytokines relevant to anti-viral 
responses and that fall into 4 groups-: interleukins (IL-1Alpha, IL-5, IL-8, IL-10, IL-12p70, IL-12/IL23p40, IL-15, IL-17A, IL-17A/F, IL-17E/IL-25, IL-18), interferons (IFN-Alpha2a, IFN-Beta, IFN-Gamma),

75 TNF-Alpha (as a member of the TNF family), and chemokines (IP-10, MCP-1, MIP-1Alpha, MIP-3Alpha, and MIP-3Beta). These were selected for their role in innate or adaptive immunity, and because of their pro-inflammatory or anti-inflammatory activity. Here, we describe their cervicovaginal secretion profile.

Using statistical single-factor tests we found that increase in IL1-Alpha and IL-12/IL-23p40 levels isare

80 associated with HPV infection, whereas increased MIP-1Alpha is associated with HR HPV genotype infections only. To take into account additional factors pertaining to perturbations of the cervicovaginal milieu, we developed a model selection approach. Results indicate a broad cytokine response to chlamydia (IP-10, MIP-3Alpha, MCP-1, TNF-Alpha, MIP-3Beta, IL-15), and bacterial vaginosis (BV) (IL-17A/F, IL-8, IL-1Alpha, IL-15). However, cytokine response associated more 85 specifically with changes in HPV infection are more limited (IL-1Alpha, IL-12/IL-23p40, IP-10, MIP3Alpha). Our results from multi-factor analysis indicate that infections with HR HPV genotypes are associated with increased IP-10, IL-5 and MIP-1Alpha. Overall, our multivariate modeling approach provides a detailed description of cytokine expression profiles with great explanatory power in young women's genital tract in the context of HPV and other genital infections. 


\section{Materials and Methods}

\subsection{Participant enrollment and sampling}

The PAPCLEAR study is a mono-centric longitudinal study run at the Montpellier STI detection center (CeGIDD). Its main objective is to decipher the kinetics of HPV genital infections in young women. The enrollment criteria and study design have been described previously.[12]

95 | During the inclusion visit, participants filled-_out online health and lifestyle questionnaires that capture a range of demographic, clinical, reproductive, and behavioral variables. Cervicovaginal secretions were collected using Weck-Cel sponges (Beaver-Visitec International) placed directly into the cervical os for approximately $1 \mathrm{~min}$. Sponges were then transferred into a Salivette ${ }^{\circledast}$ (Sarstedt) device and centrifugated at $1500 \mathrm{rpm}$ for $5 \mathrm{~min}$ at $4^{\circ} \mathrm{C}$ after the addition of $175 \mu \mathrm{L}$ of phosphate-

100 buffered saline (PBS). Supernatants were separated into $50 \mu \mathrm{L}$ aliquots and stored at $-80^{\circ} \mathrm{C}$.

\subsection{Detection of HPV DNA and other infections}

The protocols used for HPV detection and genotyping rely on the DEIA and LiPa25 tests as described previously.[13] The presence of chlamydia infection was tested by PCR following the STI detection

105 center standard procedures. Diagnosis for BV, and urinary tract, fungal, or genital infections were performed by the clinician or mid-wife during the gynecological visit.

Cytokine concentrations were analyzed at the first (inclusion) visit of 103 participants. For HPV testing and genotyping, we also used data from the second visit, a month later, to define more robust infection patterns and rule out transient HPV carriage, as detailed in an earlier study.[13]

\subsection{Measurement of cervicovaginal cytokine concentrations}

The MSD U-plex Biomarker Group 1 (human) from Meso Scale Discovery (MSD, Rockville, Maryland, USA) was used to measure 20 analytes divided into two panels: IFN-Gamma, IL-5, IL-8, IL-10, IL-12p70, IL-17A, TNF-Alpha, IP-10, MCP-1, MIP-1Alpha, and IFN-Alpha2a on one plate-; IL-1Alpha, IL-12/IL-

115 23p40, IL-15, IL-18, MIP-3Alpha, MIP-3Beta, IL-17A/F, IL-17E/IL-25, and IFN-Beta on a second plate. For each panel, we used $25 \mu \mathrm{L}$ of specimen, according to the manufacturer's instructions. Analyses were performed on a MESO QuickPlex SQ 120 reader. 


\subsection{Measurement of total protein}

120 To normalize cytokine quantitation, total protein content was measured in the same samples using the Invitrogen Qubit protein assay kit (Thermo Fisher Scientific) following the manufacturer's instructions.

\subsection{Statistical analysis}

125 To calculate cytokine sample concentrations from the standard curves, we used a four-parameter logistic regression model[36,37] implemented in R with the package minpack.Im. In order to avoid non-detectability as a confounding factor, we only kept samples for which all 20 cytokines were detectable across all participants, resulting in 92 (of initially 103) samples. We divided each concentration by the total amount of protein measured in each sample, before transforming the

130 normalized cytokine concentration to_a $\log 10$ scale. We tested each cytokine distribution for normality using the Shapiro-Wilk test. We tested for differences in cytokine concentration associated with changes regarding HPV infections using parametric (t-test for normally distributed cytokines) and non-parametric tests (else, with Wilcoxon test for all binary covariates and Kruskal-Wallis test for covariates with more than two levels).

135 We then applied linear regression models with fixed effects for combinations of covariates based on the survey conducted during the inclusion visit resulting in a set of 15 factors pertaining to infections (see Table 1 for a complete list). In these models, we were adjusting for the standard curve calibration parameter setting and the total protein quantity used for normalization. For each cytokine, we tested all $2^{15}$ covariate combinations, and among the models with at least one statistically significant factor

140 and normally distributed residuals (using a Shapiro-Wilk test criteria), we chose the one with the lowest Akaike Information Criterion (AIC) value to select the most parsimonious model.

Furthermore, associations between groups of cytokines relating to infection covariates were investigated by comparing correlation networks. Given the set of 20 nodes (i.e. cytokines), we would draw an edge between two nodes, whenever the correlation between respective concentrations was 145 statistically significant (Pearson correlation with $\mathrm{P}<0.05$ ). We then compared changes in degree 
distribution (i.e. the number of significant correlations of a cytokine with all other cytokines) between HPV positive and HPV negative samples.

In order to relate associations between cytokines to perturbations of the cervicovaginal milieu, we tested pairwise differences between cytokine concentrations with independent variables obtained

150 from the model selection procedure of fixed-effect linear models above. This approach helped identify significant changes between cytokines depending on changes in infection covariates. To summarize our results, we visualized essential cytokine network motifs. For each covariate, nodes in the motif consist of cytokines that were included in at least one univariate model containing the covariate (Figure 2A) or had at least one significant difference with a cytokine doing so. Cytokines that

155 significantly increased or decreased (resp. were not significant) in the per cytokine analysis (Figure 2A) are in red or blue (resp. grey). Increasing or decreasing differences between cytokines are marked by orange or light blue edges. To further highlight the increasing (resp. decreasing trend) of differences we added with outward (resp. inward) pointing arrows to the edges. The node position or the edge length within a motif are only part of the graphic layout and have no statistical meaning. Only motifs

160 with at least one significant difference (i.e. edge) were plotted.

All analyses were performed in R (R Development Core Team (2019). R: A Language and Environment for Statistical Computing. Vienna, Austria: R Foundation for Statistical Computing) using packages Ime4 $(\mathrm{glm})$ and stats (kruskal.test, t.test, shapiro.test, wilcox.test). Scripts and data wastll be deposited in the Zenodo repository 10.5281/zenodo.4701172.

\subsection{Ethics}

The PAPCLEAR trial is promoted by the Centre Hospitalier Universitaire (CHU) de Montpellier (France) and has been approved by the Comité de Protection des Personnes (CPP) Sud Méditerranée I on 11 May_2016 (CPP number 16 42, reference number ID RCB 2016-A00712-49); by the Comité Consultatif sur le Traitement de l'Information en matière de Recherche dans le domaine de la Santé on 12 July 2016 (reference number 16.504); and by the Commission Nationale Informatique et Libertés on 16 December 2016 (reference number MMS/ABD/AR1612278, decision number DR-2016-488). This trial was authorised by the Agence Nationale de Sécurité du Médicament et des Produits de Santé on 20 
July 2016 (reference20160072000007). The ClinicalTrials.gov identifier is NCT02946346. All partici-

175 pants provided written informed consent.

\section{$3 \quad$ Results}

\subsection{Study participants}

Clinical and demographic information of the cohort has been described previously.[13] For the subset

180 of participants in this analysis the median age was 21 years (interquartile range: 21-23 years), and 5 percent of the study participants presented atypical squamous cells of undetermined significance (ASC-US) and 4\% were diagnosed low-grade squamous intraepithelial lesions (LSIL). Forty out of 92 participants were HPV negative. The predominant HPV subtype was HPV-53 (13\%), followed by HPV$51(12 \%)$ and HPV-66 (10\%). Two out of 92 participants had BV, both co-infected with HPV, and

185 among the three participants with chlamydia diagnosis, two were co-infected with HPV.

\subsection{Genital cytokines and prevalent HPV infections}

The lower limits of detection for the cytokine concentrations ranged between $10^{\wedge}-5.8$ and $10^{\wedge} 0.8 \mathrm{pg} /$ $\mathrm{mL}$ (see supplementary table 1). The distribution of normalized cytokine concentrations varies within

190 four orders of magnitude in terms of median values and only a limited number of cytokines (MIP1Alpha, IL-10, and IFN-Beta) are undetectable in 6-7\% of the samples (Figure S1). Statistical tests suggest that several cytokines are not normally distributed (cytokines with low Shapiro-Wilk p-values, Figure S2) therefore we conducted suitable statistical single-factor tests relevant for HPV infections (Figure S3). Our results reveal that an increase in IL1-Alpha and IL-12/IL-23p40 concentration is

195 associated with HPV positivity and clearance, whereas increases in MIP1-Alpha, IL1-Alpha-, and IL-12/IL-23p40 concentrations are significantly associated with infection with HR HPV genotypes compared to low-risk genotypes or no HPV infection (Figure 1).

\subsection{Interplay between infection-related factors and cytokine response}

200 To assess whether infection-related covariates produce a more generic cytokine response, we exhaustively tested 15 factors using linear models (see Material and Methods). Filtering models with 
at least one statistically significant covariate suggests that models combining between 10 and 12 factors were more likely to reveal significant associations (Figure S4).

The model selection approach used to determine the most parsimonious combination of covariates

205 (Figure 2A) shows a broad panel of cytokines increasing in response to chlamydia (IP-10, MIP-3Beta, MCP-1, TNF-Alpha, MIP-3Alpha, IL-15) and, to a lesser extent, to BV (IL-17A/F, IL-8, IL-1Alpha, IL-15). Regarding, more specifically, the presence of an HPV infection, we find an increase of IL-1Alpha and IL-12/IL-23p40, as well as a reduction of IP-10 and MIP-3Alpha.

Infection with HR HPV genotypes is associated with increased levels of IP-10, IL-5, and MIP-1Alpha.

210 Also, a majority of parsimonious models comprise covariates related to inflammatory perturbations (e.g. genital and urinary infections, pelvic inflammation). Although they are not significant by themselves, their contribution to the model selection process (Figure 2A, crossed fields) helps disentangle whether effects are related to HPV infection or not. E.g. the increase in IL-1Alpha for HPV positive participants was also impacted, but not significantly, by pelvic inflammation and genital 215 infection status, and vaginal secretions.

\subsection{Cytokine network motifs}

To investigate the relationship between cytokines, we first estimated correlation networks based on HPV infection status. The network degree of a particular node, which corresponds to a cytokine, is

220 given by the number of other cytokines it is significantly correlated with. The most striking difference between the HPV-positive and the HPV-negative network was found for MIP-3Beta and MIP-3Alpha (Figure 2B). For HPV positive participants, these two cytokines were highly correlated with most other cytokines in the panel, whereas for HPV negative participants, significant correlations were largely absent. On the other hand, the number of cytokines correlated with IL-5 and IL-1Alpha increased for

225 the HPV negative group when compared to HPV positive subjects (Figure 2B).

To evaluate the relationship between cytokines beyond correlations, we tested for changes in pairwise differences between cytokines using covariate combinations that have been selected in the multi-variate analysis from the preceding paragraph. Unlike correlations, which concern parallel trends, this approach allows to testing whether the difference in concentration between two 230 cytokines changes according to infection conditions. We found that MIP-3Alpha and IL-1Alpha (Figure 
3) have highly contrasting roles in the cytokine network when HPV infection status changes. In particular, an IL-1Alpha increase is strongly associated with a MIP-3Alpha decrease, but with decreasing difference between the two cytokines (Figure 3, HPV+ panel with inward--pointing arrows). On the other hand, the concurrent increase of IL-12/IL-23p40 and IL1-Alpha occurred with

235 significantly increasing difference (Figure 3, HPV+ panel with outward--pointing arrows). Similarly, the (self-reported) absence of HPV infection history prior to entry in the clinical study shows significant differences between IL-17A/F, IL-12p70 and IL-17E/IL-25. Interestingly, other covariates involving HPV status (multiple infections, HR-HPV genotypes) do not display significant network motifs, although each of them has at least one significantly different cytokine when tested alone. Chlamydia and BV

240 covariates show the most striking network motifs, albeit with low propensity in the study population (3\% and $2 \%$, respectively).

\section{Discussion}

Incident genital HPV infections in young women, especially in the absence of abnormal cervical

245 cytology, have rarely been studied in vivo.[14,15] To further our understanding of the natural history of such infections, it is necessary to characterize the host immune response, as persistent HPV infections have been hypothesized to evade the host immune system by modulating cytokine production and impairing pro-inflammatory responses.[7,16]

Determining signatures of cervicovaginal cytokine response to HPV infection has not yet reached 250 consensus in the research community.[17-20] The challenges are numerous and at various scales, ranging from cellular heterogeneity of solid tissue and non-detectability, to demographic and behavioral determinants. The PAPCLEAR cohort[12] had been set up prospectively to yield a fairly homogeneous study population in terms of age, sexual activity and thus exposure history prior to enrollment. Incidentally, it also turned out to be well-balanced in terms of HPV infections such that it

255 constitutes an opportunity to measure local immune mediators, such as cytokines, taking also into account covariates pertaining to microbial perturbations of the cervicovaginal environment. These include HPV infections, BV, chlamydia but also associated self-reported symptoms (odors, itching, etc.). 
A high concentration of IL-1Alpha pro-inflammatory cytokine was detected in the cervicovaginal

260 environment of our healthy cohort and it was significantly associated with HPV infection and clearance. This is consistent with the fact that this cytokine is produced by keratinocytes and is a crucial mediator of the antigen recognition process by Langerhans cells that migrate then to draining lymph nodes. This result is in line with reports[21,22] hethat detected significantly higher levels of inflammatory mediators including IL-1Alpha in vaginal swabs collected from sexually active compared 265 to sexually inactive girls.

Although we can statistically corroborate the association of several cytokines (IL-1Alpha, IL-12/IL23p40, MIP-1Alpha) with HPV infection,[18] these were not confirmed by a recent study[19] focusing on the link between the persistence of HPV infections and pro-inflammatory cytokines (including IL1Alpha, IL-10, IL-17, and TNF-Alpha). This difference could be due to bias in the ethnic origin of the 270 participants, sampling method (self-collection in Softcups versus gynecologist Weck-Cel sponge collection in our study) or concentration normalization methods. Note also that cervical IL-1Alpha concentrations vary during the menstrual cycle[23] with a potential protective role against bacterial invasion into the uterine cervix.[24]

We also detected novel significant association $\underline{s}$ between the presence of HR-HPV genotypes and the 275 MIP-1Alpha chemokine, as well as the IL-12/IL-23p40 interleukin. IL-12 is an important regulator of T-cell functions, known to promote T-helper-1 cell development, and IL23 is a major inducer of IL-17. These data are consistent with the reported locally immunosuppressive function of IL-17 in HPVassociated premalignant disease.[25,26]

The assessment of cytokine responses revealed that specific soluble immune mediators, mainly 280 chemokines (IP10, MIP-3Beta, MCP-1, and MIP-3Alpha) are positively associated with chlamydia infection. Chemokines are small cationic molecules that link innate and adaptive immune responses by attracting effector cells to the site of infection. Chemokines such as MIP-3Alpha are known to act as an-antimicrobial agent.[27] Similarly, the Th1-associated chemokines IP-10 and MCP-1 have been reported to be important in immunity against chlamydia.[28,29] Our results point also to the known 285 involvement of NK-cells via the action of IL-15 and TNF-Alpha[30], which we found both associated with significant effects. 
BV is the most common vaginal infection in women of reproductive age and is associated with an increased risk of acquiring sexually transmitted infections including HPV infections.[31] Among the cytokines, we found that a BV diagnosis was significantly associated with the presence of IL-1Alpha,

290 consistently with earlier results.[32] Overall, our findings are consistent with the cytokine signatures defined by Masson and colleagues[33] with chlamydia being associated with the highest genital cytokine levels and BV-infected women displaying a mixed genital cytokine profile, with increased proinflammatory cytokine concentration.

\section{Conclusion}

We extended prior analyses by investigating the interplay between cytokines depending on microbial perturbations in two ways. First, our statistical analysis was able to integrate combinations of covariates in order to yield for each cytokine the most parsimonious descriptors with an optimal trade-off between predictive power and degrees of freedom. Second, correlation network analysis confirmed the central role played by IL-1Alpha. Network motif analysis showed that IL-12/IL-23p40 not only increased concurrently with IL-1Alpha; but that their difference was also increasing, suggesting non-linear relationships.

Functional interpretation remains a major limitation of our study, since pathway analysis based on expression patterns[34] typically requires several hundred transcripts from host mRNA, and has also

305 to account for microbial community states.[35] We deliberately limited our analysis to covariates related to microbial perturbations, since extending this approach to other covariates (e.g. vaccination or sexual behavior) would likely result in model overfitting, given the size of the cohort.

A perspective of this study will be to perform longitudinal analyses on the PAPCLEAR cohort data. It will be particularly informative to investigate how the dynamics of the cytokines strongly associated with HPV infection (e.g. IP-10, MIP-3Alpha, and IL-1Alpha) correlates with viral load dynamics. This would allow us to go beyond the correlation and identify whether the expression patterns we identify are associated with an increased risk for HPV infection or a response to HPV infection. Furthermore, the study will also describe vaginal microbiota compositions. In order to maximize HPV clearance, a promising research area would be the use of personalized probiotics combined with recombinant 315 human IL-1Alpha. Additionally, the vaginal microbiome profiling of our cohort could shed light on the 
impact of chlamydia or BV in an HPV context. Taken together, our analysis revealed novel cytokines involved in local immune responses to acute HR-HPV infection and confirmed the central role played by IL-1Alpha more generally toward HPV infection. 


\section{Tables and figure captions}

Table 1: Covariates related to infections

\begin{tabular}{|c|c|c|c|c|}
\hline Covariate name & Data type & Levels & Description & Source \\
\hline $\mathrm{HPV}+$ & binary & yes/no & $\begin{array}{l}\text { DEIA positive for at least one HPV } \\
\text { genotype }\end{array}$ & Laboratory testing \\
\hline Multiple HPV+ & binary & yes/no & $\begin{array}{l}\text { DEIA positive for more than one } \\
\text { HPV genotype }\end{array}$ & Laboratory testing \\
\hline Ever HPV+ & binary & yes/no & $\begin{array}{l}\text { Any occurrence of HPV infection in } \\
\text { the past }\end{array}$ & $\begin{array}{l}\text { Questionnaire at } \\
\text { inclusion visit }\end{array}$ \\
\hline HPV Pattern & categorical & $\begin{array}{l}0 \_0, \quad 0 \_1 \\
1 \_0,1 \_1\end{array}$ & $\begin{array}{l}\text { A_B means infection status } A \text { at } \\
\text { visit } 1 \text { and } B \text { at visit } 2 ; 0=D E I A \\
\text { negative for } t \text { at least one } \\
\text { genotype; } 1=D E I A \text { positive for at } \\
\text { least one genotype }\end{array}$ & Laboratory testing \\
\hline Has high risk HPV+ & binary & yes/no & $\begin{array}{l}\text { Following high risk of } \\
\text { carcinogenesis: HPV genotypes } 16 \text {, } \\
18,31,33,35,39,45,51,52,56, \\
58,59 \\
\text { no includes HPV negatives and non- } \\
\text { high-risk positives }\end{array}$ & esting \\
\hline Vaginosis+ & binary & yes/no & $\begin{array}{l}\text { Any bacterial vaginosis diagnosis } \\
\text { during the past three months }\end{array}$ & $\begin{array}{l}\text { Questionnaire at } \\
\text { inclusion visit }\end{array}$ \\
\hline Chlamydia+ & binary & yes/no & $\begin{array}{l}\text { Either tested in the past three } \\
\text { months, if not, then tested at } \\
\text { inclusion visit }\end{array}$ & $\begin{array}{l}\text { CeGIDD screening } \\
\text { at inclusion visit }\end{array}$ \\
\hline
\end{tabular}




\begin{tabular}{|c|c|c|c|c|}
\hline $\begin{array}{l}\text { Urinary } \\
\text { infection+ }\end{array}$ & binary & yes/no & $\begin{array}{l}\text { Any urinary infection diagnosis } \\
\text { during the past three months }\end{array}$ & $\begin{array}{l}\text { Questionnaire at } \\
\text { inclusion visit }\end{array}$ \\
\hline Fungal Infection+ & binary & yes/no & $\begin{array}{l}\text { Any fungal infection diagnosis } \\
\text { during the past three months }\end{array}$ & $\begin{array}{l}\text { Questionnaire } \\
\text { inclusion visit }\end{array}$ \\
\hline Genital infection+ & binary & yes/no & $\begin{array}{l}\text { told by a health professional during } \\
\text { your lifetime (and last three } \\
\text { months) }\end{array}$ & $\begin{array}{l}\text { Questionnaire } \\
\text { inclusion visit }\end{array}$ \\
\hline Itching+ & binary & Yes/no & $\begin{array}{l}\text { Any itching during the past two } \\
\text { weeks months }\end{array}$ & $\begin{array}{l}\text { Questionnaire } \\
\text { inclusion visit }\end{array}$ \\
\hline Vaginal odors+ & binary & yes/no & $\begin{array}{l}\text { Any unusual vaginal odors during } \\
\text { the past two weeks }\end{array}$ & $\begin{array}{l}\text { Questionnaire } \\
\text { inclusion visit }\end{array}$ \\
\hline Douching+ & binary & yes/no & $\begin{array}{l}\text { Any douching during the past two } \\
\text { weeks }\end{array}$ & $\begin{array}{l}\text { Questionnaire } \\
\text { inclusion visit }\end{array}$ \\
\hline Pelvic inflammation+ & binary & yes/no & $\begin{array}{l}\text { Any pelvic inflammation diagnosis } \\
\text { during the past three months }\end{array}$ & $\begin{array}{l}\text { Questionnaire } \\
\text { inclusion visit }\end{array}$ \\
\hline Vaginal secretions+ & binary & yes/no & $\begin{array}{l}\text { Any vaginal secretion during the } \\
\text { past two weeks }\end{array}$ & $\begin{array}{l}\text { Questionnaire at } \\
\text { inclusion visit }\end{array}$ \\
\hline
\end{tabular}

325 


\section{Figure captions}

Figure 1: Single-factor statistical tests for cytokine changes with respect to HPV infection status. Black dots show data, the red dot is the median, and the red line the standard deviation for each group. Tests were chosen according to normality (see Figure S2). We show only results with a p-value less or 340 equal 0.1.

Figure 2: Panel A: The heatmap shows for each cytokine the most parsimonious linear model with increasing (red) and decreasing (blue) cytokine levels depending on infection covariate levels (columns, negative or absence considered as reference level). Crosses indicate the presence of a

345 covariate in the selected model without being itself statistically significant. The propensity score indicates the percentage of a covariate level within the study population. Panel B: Degree distribution of cytokine correlation graphs for HPV positive (red) and HPV negative (turquoise) samples. Correlations were calculated using Pearson correlation p-values, the degree for a particular cytokine is defined as the number of correlated $(P<0.05)$ cytokines.

Figure 3: Network motifs of significant differences between cytokine concentrations. For each covariate, nodes in the motif correspond to cytokines that were included in at least one univariate model containing the covariate (Figure $2 \mathrm{~A}$ ) or had at least one significant difference with such a cytokine. Cytokines that significantly increased or decreased (resp. were not significant) in the per cytokine analysis (Figure 2A) are in red or blue (resp. grey). Increasing or decreasing differences between cytokines are marked by orange (with outward--pointing arrows) or light blue edges (with inward--_pointing arrows).

Figure S1: Detection propensity for cytokines in 103 initial samples.

Figure S2: Distribution of normalized cytokine concentrations (log10) for complete observations with p-values from the Shapiro-Wilk test, $\mathrm{P}<0.05$ indicating non-Gaussian distribution. 
Figure S3: Results of statistical tests for HPV infection covariates using parametric (t-test for normally 365 distributed cytokines) and non-parametric tests (Wilcoxon test for all binary covariates, Kruskal-Wallis test for covariates with more than two levels for non-Gaussian distributions).

Figure S4: Number of linear models with at least one statistically significant covariate, with normally (turquoise) and not normally (red) distributed residuals depending on the number of covariates in 370 each model. 


\section{Declarations}

\section{$380 \quad$ Funding}

This work was supported by the European Research Council (ERC) under the European Union's Horizon 2020 research and innovation program [grant agreement No 648963 to SA]. The sponsor had no role in study design, in the collection, analysis and interpretation of data, in the writing of the report and in the decision to submit the article for publication.

Conflict of interest/Competing interest

390 The authors declare no conflict of interest.

\section{Availability of data and material}

The data will be deposited at Zenodo repository.

\section{Code availability}

The $\mathrm{R}$ code for the statistical analysis will be deposited at Zenodo repository.

\section{Authors' contribution}

Conceived or designed the study: SA, CLM, CH, NJ, JR

400 Wrote the paper: SA, CS, MR, CLM, NJ 
Performed research: MR, CB, VB, Soraya G, SG, CG, MB

Contributed new methods or models: CS, MR

Analyzed data: CS 


\section{Acknowledgments}

The authors acknowledge the IRD itrop HPC (South Green Platform) at IRD Montpellier for providing HPC resources that have contributed to the research results reported within this paper (URL: http://www.southgreen.fr ).

We also acknowledge productive feedback on the manuscript by Nicolas Tessandier. 
[1] C. de Martel, M. Plummer, J. Vignat, S. Franceschi, Worldwide burden of cancer attributable to HPV by site, country and HPV type, International Journal of Cancer. 141 (2017) 664-670. https:// doi.org/10.1002/ijc.30716.

[2] M. Schiffman, P.E. Castle, J. Jeronimo, A.C. Rodriguez, S. Wacholder, Human papillomavirus and cervical cancer, Lancet. 370 (2007) 890-907. https://doi.org/10.1016/S0140-6736(07)61416-0.

[3] A.C. Rodríguez, M. Schiffman, R. Herrero, S. Wacholder, A. Hildesheim, P.E. Castle, D. Solomon, R. Burk, Proyecto Epidemiológico Guanacaste Group, Rapid clearance of human papillomavirus and implications for clinical focus on persistent infections, J. Natl. Cancer Inst. 100 (2008) 513517. https://doi.org/10.1093/jnci/djn044.

[4] IARC working group on the evaluation of carcinogenic risks to humans: occupational exposures of hairdressers and barbers and personal use of hair colourants; some hair dyes, cosmetic colourants, industrial dyestuffs and aromatic amines. Proceedings. Lyon, France, 6-13 October 1992, IARC Monogr Eval Carcinog Risks Hum. 57 (1993) 7-398.

[5] A. Steinbach, A.B. Riemer, Immune evasion mechanisms of human papillomavirus: An update, Int. J. Cancer. 142 (2018) 224-229. https://doi.org/10.1002/ijc.31027.

[6] K. Nasu, H. Narahara, Pattern Recognition via the Toll-Like Receptor System in the Human Female Genital Tract, Mediators of Inflammation. 2010 (2010). https://doi.org/10.1155/2010/976024.

[7] A. Amador-Molina, J.F. Hernández-Valencia, E. Lamoyi, A. Contreras-Paredes, M. Lizano, Role of Innate Immunity against Human Papillomavirus (HPV) Infections and Effect of Adjuvants in Promoting Specific Immune Response, Viruses. 5 (2013) 2624-2642. https://doi.org/10.3390/v5112624.

[8] R.A.L. Nunes, M.G. Morale, G.Á.F. Silva, L.L. Villa, L. Termini, Innate immunity and HPV: friends or foes, Clinics (Sao Paulo). 73 (2018) e549s. https://doi.org/10.6061/clinics/2018/e549s.

[9] M. Stanley, Immunology of HPV Infection, Curr Obstet Gynecol Rep. 4 (2015) 195-200. https://doi.org/10.1007/s13669-015-0134-y.

[10] P. Leone, E.-C. Shin, F. Perosa, A. Vacca, F. Dammacco, V. Racanelli, MHC class I antigen processing and presenting machinery: organization, function, and defects in tumor cells, J. Natl. Cancer Inst. 105 (2013) 1172-1187. https://doi.org/10.1093/jnci/djt184.

[11] S. Alizon, C.L. Murall, I.G. Bravo, Why Human Papillomavirus Acute Infections Matter, Viruses. 9 (2017) 293. https://doi.org/10.3390/v9100293.

[12] C.L. Murall, M. Rahmoun, C. Selinger, M. Baldellou, C. Bernat, M. Bonneau, V. Boué, M. Buisson, G. Christophe, G. D'Auria, F.D. Taroni, V. Foulongne, R. Froissart, C. Graf, S. Grasset, S. Groc, C. Hirtz, A. Jaussent, J. Lajoie, F. Lorcy, E. Picot, M.-C. Picot, J. Ravel, J. Reynes, T. Rousset, A. Seddiki, M. Teirlinck, V. Tribout, É. Tuaillon, T. Waterboer, N. Jacobs, I.G. Bravo, M. Segondy, N. Boulle, S. Alizon, Natural history, dynamics, and ecology of human papillomaviruses in genital infections of young women: protocol of the PAPCLEAR cohort study, BMJ Open. 9 (2019) e025129. https://doi.org/10.1136/bmjopen-2018-025129.

[13] C.L. Murall, B. Reyné, C. Selinger, C. Bernat, V. Boué, S. Grasset, S. Groc, M. Rahmoun, N. Bender, M. Bonneau, V. Foulongne, C. Graf, E. Picot, M.-C. Picot, V. Tribout, T. Waterboer, I.G. Bravo, J. Reynes, M. Segondy, N. Boulle, S. Alizon, HPV cervical infections and serological status in 
vaccinated and unvaccinated women, Vaccine. 38 (2020) 8167-8174.

https://doi.org/10.1016/j.vaccine.2020.10.078.

[14] A.B. Moscicki, S. Shiboski, J. Broering, K. Powell, L. Clayton, N. Jay, T.M. Darragh, R. Brescia, S. Kanowitz, S.B. Miller, J. Stone, E. Hanson, J. Palefsky, The natural history of human papillomavirus infection as measured by repeated DNA testing in adolescent and young women, J Pediatr. 132 (1998) 277-284. https://doi.org/10.1016/s0022-3476(98)70445-7.

[15] N. Zanotta, M.L. Tornesello, C. Annunziata, G. Stellato, F.M. Buonaguro, M. Comar, Candidate Soluble Immune Mediators in Young Women with High-Risk Human Papillomavirus Infection: High Expression of Chemokines Promoting Angiogenesis and Cell Proliferation, PLoS One. 11 (2016) e0151851. https://doi.org/10.1371/journal.pone.0151851.

[16] B. Tummers, S.H. Van Der Burg, High-Risk Human Papillomavirus Targets Crossroads in Immune Signaling, Viruses. 7 (2015) 2485-2506. https://doi.org/10.3390/v7052485.

[17] A.P.M. Fernandes, M.A.G. Gonçalves, G. Duarte, F.Q. Cunha, R.T. Simões, E.A. Donadi, HPV16, HPV18, and HIV infection may influence cervical cytokine intralesional levels, Virology. 334 (2005) 294-298. https://doi.org/10.1016/j.virol.2005.01.029.

[18] L.J.P. Liebenberg, L.R. McKinnon, N. Yende-Zuma, N. Garrett, C. Baxter, A.B.M. Kharsany, D. Archary, A. Rositch, N. Samsunder, L.E. Mansoor, J.-A.S. Passmore, S.S. Abdool Karim, Q. Abdool Karim, HPV infection and the genital cytokine milieu in women at high risk of HIV acquisition, Nat Commun. 10 (2019) 5227. https://doi.org/10.1038/s41467-019-13089-2.

[19] B. Shannon, T.J. Yi, S. Perusini, P. Gajer, B. Ma, M.S. Humphrys, J. Thomas-Pavanel, L. Chieza, P. Janakiram, M. Saunders, W. Tharao, S. Huibner, K. Shahabi, J. Ravel, A. Rebbapragada, R. Kaul, Association of HPV infection and clearance with cervicovaginal immunology and the vaginal microbiota, Mucosal Immunol. 10 (2017) 1310-1319. https://doi.org/10.1038/mi.2016.129.

[20] A.-B. Moscicki, B. Shi, H. Huang, E. Barnard, H. Li, Cervical-Vaginal Microbiome and Associated Cytokine Profiles in a Prospective Study of HPV 16 Acquisition, Persistence, and Clearance, Front. Cell. Infect. Microbiol. 10 (2020). https://doi.org/10.3389/fcimb.2020.569022.

[21] V. Jespers, L. Hardy, J. Buyze, J. Loos, A. Buvé, T. Crucitti, Association of Sexual Debut in Adolescents With Microbiota and Inflammatory Markers, Obstet Gynecol. 128 (2016) 22-31. https://doi.org/10.1097/AOG.0000000000001468.

[22] M. Ghosh, M. Jais, R. Biswas, J. Jarin, J. Daniels, C. Joy, M. Juzumaite, V. Emmanuel, V. GomezLobo, Immune biomarkers and anti-HIV activity in the reproductive tract of sexually active and sexually inactive adolescent girls, Am J Reprod Immunol. 79 (2018) e12846. https://doi.org/10.1111/aji.12846.

[23] G. Boily-Larouche, J. Lajoie, B. Dufault, K. Omollo, J. Cheruiyot, J. Njoki, M. Kowatsch, M. Kimani, J. Kimani, J. Oyugi, K.R. Fowke, Characterization of the Genital Mucosa Immune Profile to Distinguish Phases of the Menstrual Cycle: Implications for HIV Susceptibility, J Infect Dis. 219 (2019) 856-866. https://doi.org/10.1093/infdis/jiy585.

[24] T. Kanai, M. Fukuda-Miki, K. Shimoya, C. Azuma, K. Hashimoto, T. Nobunaga, Y. Tokugawa, M. Tsujimoto, F. Saji, Y. Murata, Increased interleukin-1 and interleukin-1 receptor antagonist levels in cervical mucus in the ovulatory phase in comparison with the follicular phase, Gynecol Obstet Invest. 43 (1997) 166-170. https://doi.org/10.1159/000291847.

[25] C. Gosmann, S.R. Mattarollo, J.A. Bridge, I.H. Frazer, A. Blumenthal, IL-17 suppresses immune effector functions in human papillomavirus-associated epithelial hyperplasia, J Immunol. 193 (2014) 2248-2257. https://doi.org/10.4049/jimmunol.1400216. 
[26] D.V. Hede, B. Polese, C. Humblet, A. Wilharm, V. Renoux, E. Dortu, L. de Leval, P. Delvenne, C.J. Desmet, F. Bureau, D. Vermijlen, N. Jacobs, Human papillomavirus oncoproteins induce a reorganization of epithelial-associated $\gamma \delta$ T cells promoting tumor formation, PNAS. 114 (2017) E9056-E9065. https://doi.org/10.1073/pnas.1712883114.

[27] D. Yang, Q. Chen, D.M. Hoover, P. Staley, K.D. Tucker, J. Lubkowski, J.J. Oppenheim, Many chemokines including CCL20/MIP-3a display antimicrobial activity, Journal of Leukocyte Biology. 74 (2003) 448-455. https://doi.org/10.1189/jlb.0103024.

[28] T. Belay, F.O. Eko, G.A. Ananaba, S. Bowers, T. Moore, D. Lyn, J.U. Igietseme, Chemokine and Chemokine Receptor Dynamics during Genital Chlamydial Infection, Infection and Immunity. 70 (2002) 844-850. https://doi.org/10.1128/IAI.70.2.844-850.2002.

[29] T.B. Poston, D.E. Lee, T. Darville, W. Zhong, L. Dong, C.M. O'Connell, H.C. Wiesenfeld, S.L. Hillier, G.D. Sempowski, X. Zheng, Cervical Cytokines Associated With Chlamydia trachomatis Susceptibility and Protection, J Infect Dis. 220 (2019) 330-339. https://doi.org/10.1093/infdis/jiz087.

[30] N. Radomski, A. Karger, K. Franzke, E. Liebler-Tenorio, R. Jahnke, S. Matthiesen, M.R. Knittler, Chlamydia psittaci-Infected Dendritic Cells Communicate with NK Cells via Exosomes To Activate Antibacterial Immunity, Infect Immun. 88 (2019). https://doi.org/10.1128/IAI.00541-19.

[31] E. Gillet, J.F. Meys, H. Verstraelen, C. Bosire, P. De Sutter, M. Temmerman, D.V. Broeck, Bacterial vaginosis is associated with uterine cervical human papillomavirus infection: a meta-analysis, BMC Infect Dis. 11 (2011) 10. https://doi.org/10.1186/1471-2334-11-10.

[32] F. De Seta, G. Campisciano, N. Zanotta, G. Ricci, M. Comar, The Vaginal Community State Types Microbiome-Immune Network as Key Factor for Bacterial Vaginosis and Aerobic Vaginitis, Front Microbiol. 10 (2019) 2451. https://doi.org/10.3389/fmicb.2019.02451.

[33] L. Masson, K. Mlisana, F. Little, L. Werner, N.N. Mkhize, K. Ronacher, H. Gamieldien, C. Williamson, L.R. Mckinnon, G. Walzl, Q. Abdool Karim, S.S. Abdool Karim, J.-A.S. Passmore, Defining genital tract cytokine signatures of sexually transmitted infections and bacterial vaginosis in women at high risk of HIV infection: a cross-sectional study, Sex Transm Infect. 90 (2014) 580-587. https://doi.org/10.1136/sextrans-2014-051601.

[34] C. Selinger, J. Tisoncik-Go, V.D. Menachery, S. Agnihothram, G.L. Law, J. Chang, S.M. Kelly, P. Sova, R.S. Baric, M.G. Katze, Cytokine systems approach demonstrates differences in innate and pro-inflammatory host responses between genetically distinct MERS-CoV isolates, BMC Genomics. 15 (2014) 1161. https://doi.org/10.1186/1471-2164-15-1161.

[35] M.A. Elovitz, P. Gajer, V. Riis, A.G. Brown, M.S. Humphrys, J.B. Holm, J. Ravel, Cervicovaginal microbiota and local immune response modulate the risk of spontaneous preterm delivery, Nature Communications. 10 (2019) 1305. https://doi.org/10.1038/s41467-019-09285-9.

[36] J. Dunn, D. Wild, Chapter 3.6 - Calibration Curve Fitting, in: D. Wild (Ed.), The Immunoassay Handbook (Fourth Edition), Elsevier, Oxford, 2013: pp. 323-336. https://doi.org/10.1016/B9780-08-097037-0.00022-1.

[37] M.A. O'Connell, B.A. Belanger, P.D. Haaland, Calibration and assay development using the fourparameter logistic model, Chemometrics and Intelligent Laboratory Systems. 20 (1993) 97-114. https://doi.org/10.1016/0169-7439(93)80008-6. 
415 
A

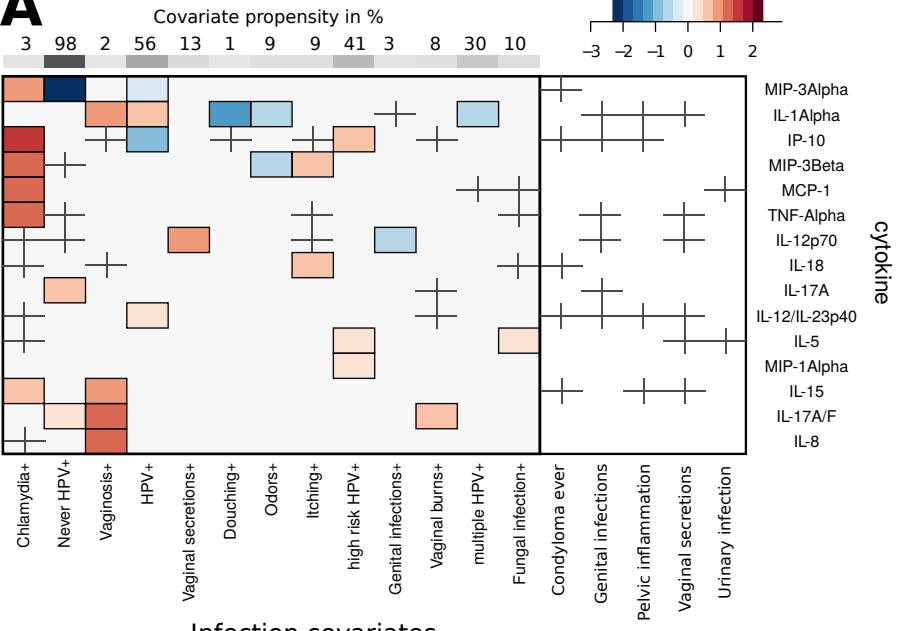

B

Infection covariates

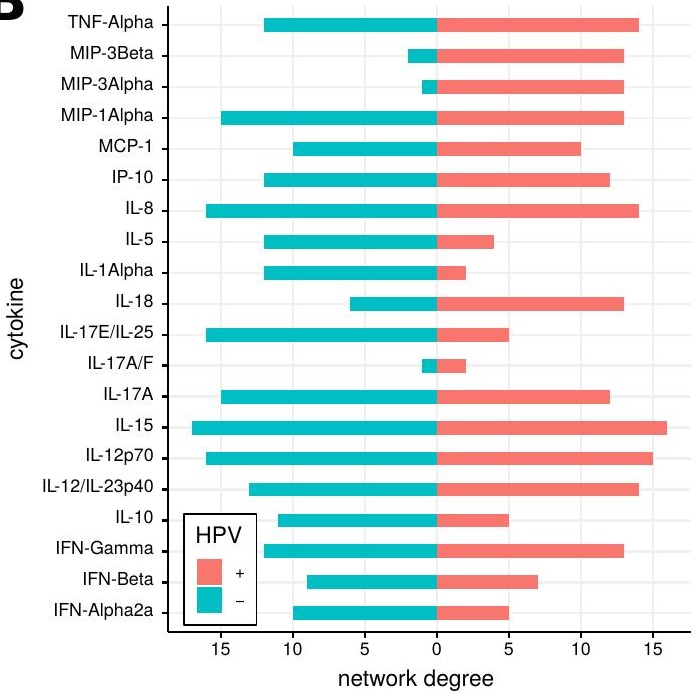




\section{IL-1Alpha}

IL-12/IL-23p40

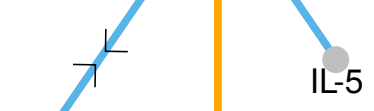

RIP-3Alpha

IFN-Alpha2a

$\mathrm{HPV}+$

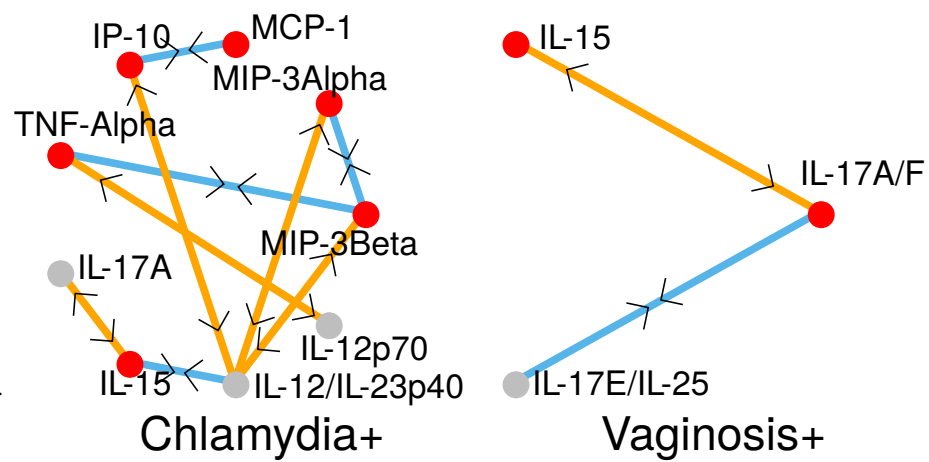

IL-17A/F

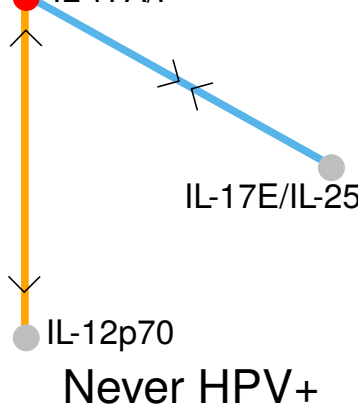

MIP-3Beta

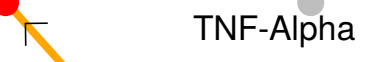

IL-17A/F

Itching+
IFN-Alpha2a

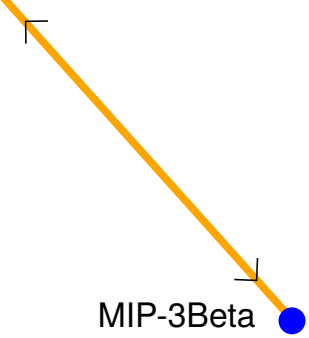

Odors+
IFN-Alpha2a

Pair-wise difference

$\longleftrightarrow\rangle$ increasing decreasing

Per cytokine

increase

- decrease

IL-5

Fungal infection+ 


\section{Supplementary Material}

Christian Selinger*, Massilva Rahmoun*, Carmen Lia Murall, Claire Bernat, Vanina Boué, Marine Bonneau, Christelle Graf, Sophie Grasset, Soraya Groc, Jacques Reynes, Christophe Hirtz, Nathalie Jacobs, Samuel Alizon: Cytokine response following perturbation of the cervicovaginal milieu during HPV genital infection

* contributed equally

Supplementary table 1: Lower limits of cytokine concentration $(\log 10)$

$\begin{array}{lc}\text { IL-10 } & -4.75 \\ \text { IL-15 } & -3.48 \\ \text { IL-5 } & -2.63 \\ \text { IL-12p70 } & -3.29 \\ \text { IL-17E/IL-25 } & -4.19 \\ \text { IL-17A/F } & -2.56 \\ \text { TNF-Alpha } & -3.44 \\ \text { IL-12/IL-23p40 } & -3 \\ \text { IFN-Alpha2a } & -2.99 \\ \text { IFN-Gamma } & -4.27 \\ \text { IFN-Beta } & -5.8 \\ \text { MIP-3Beta } & -2.02 \\ \text { IL-17A } & -2.55 \\ \text { MIP-1Alpha } & -2.83 \\ \text { MCP-1 } & -0.82 \\ \text { MIP-3Alpha } & -2.31 \\ \text { IL-1Alpha } & 0.8 \\ \text { IL-18 } & -0.1 \\ \text { IP-10 } & -0.86 \\ \text { IL-8 } & 0.49\end{array}$


Supplementary Figure 1: Detection propensity for cytokines in 103 initial samples.

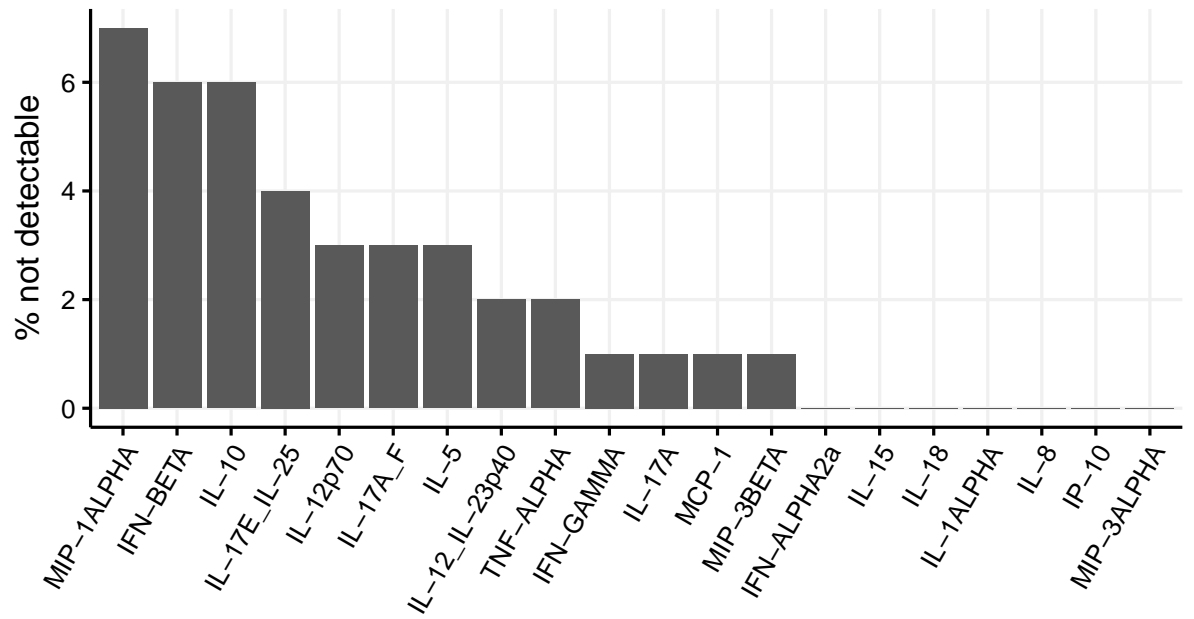

cytokine

Supplementary Figure 2: Distribution of normalized cytokine concentrations $(\log 10)$ for complete observations with p-values from the Shapiro-Wilk test, $\mathrm{P} \nmid 0.05$ indicating non-Gaussian distribution.

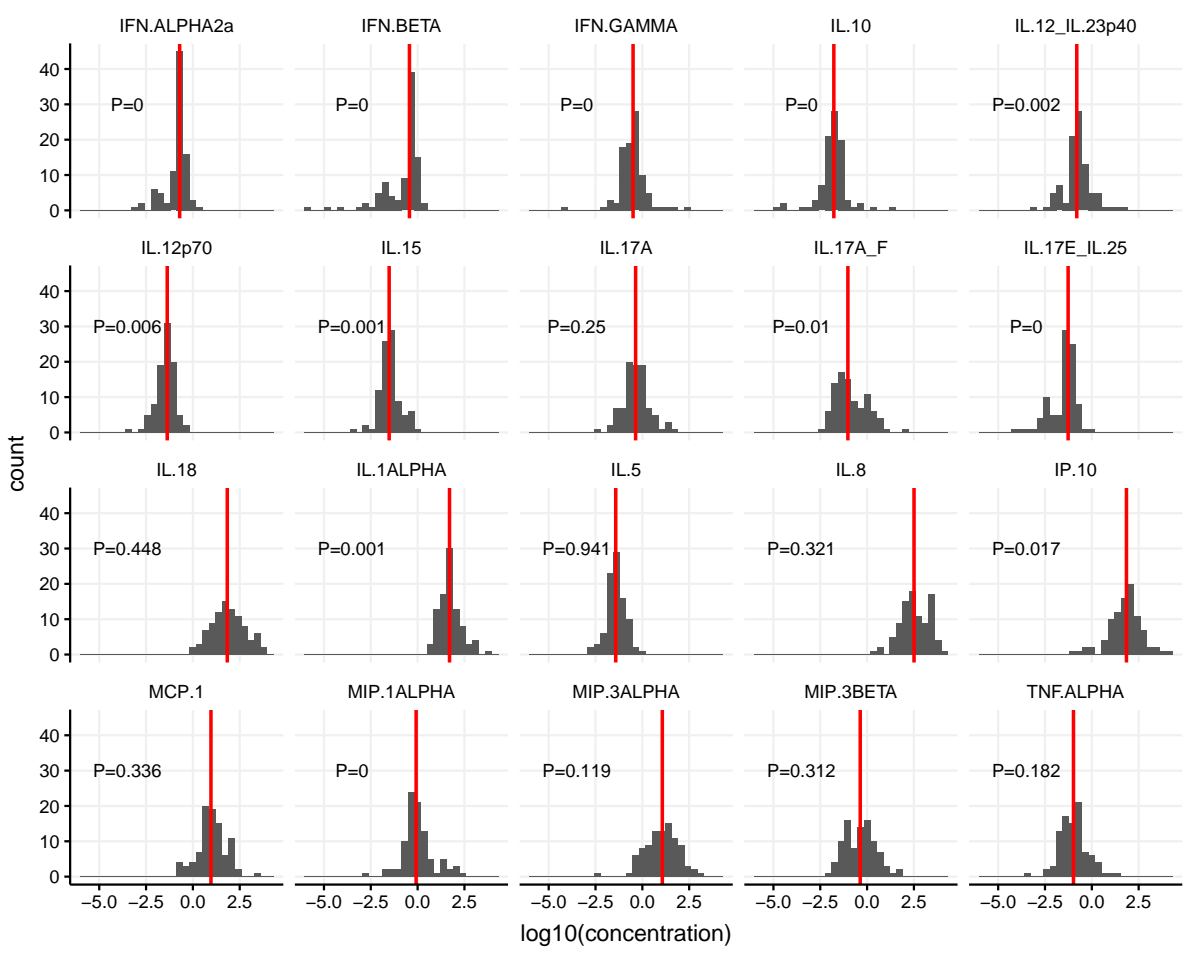


Supplementary Figure 3: Results of statistical tests for HPV infection covariates using parametric (t-test for normally distributed cytokines) and non-parametric tests (Wilcoxon test for all binary covariates, Kruskal-Wallis test for covariates with more than two levels for non-Gaussian distributions).

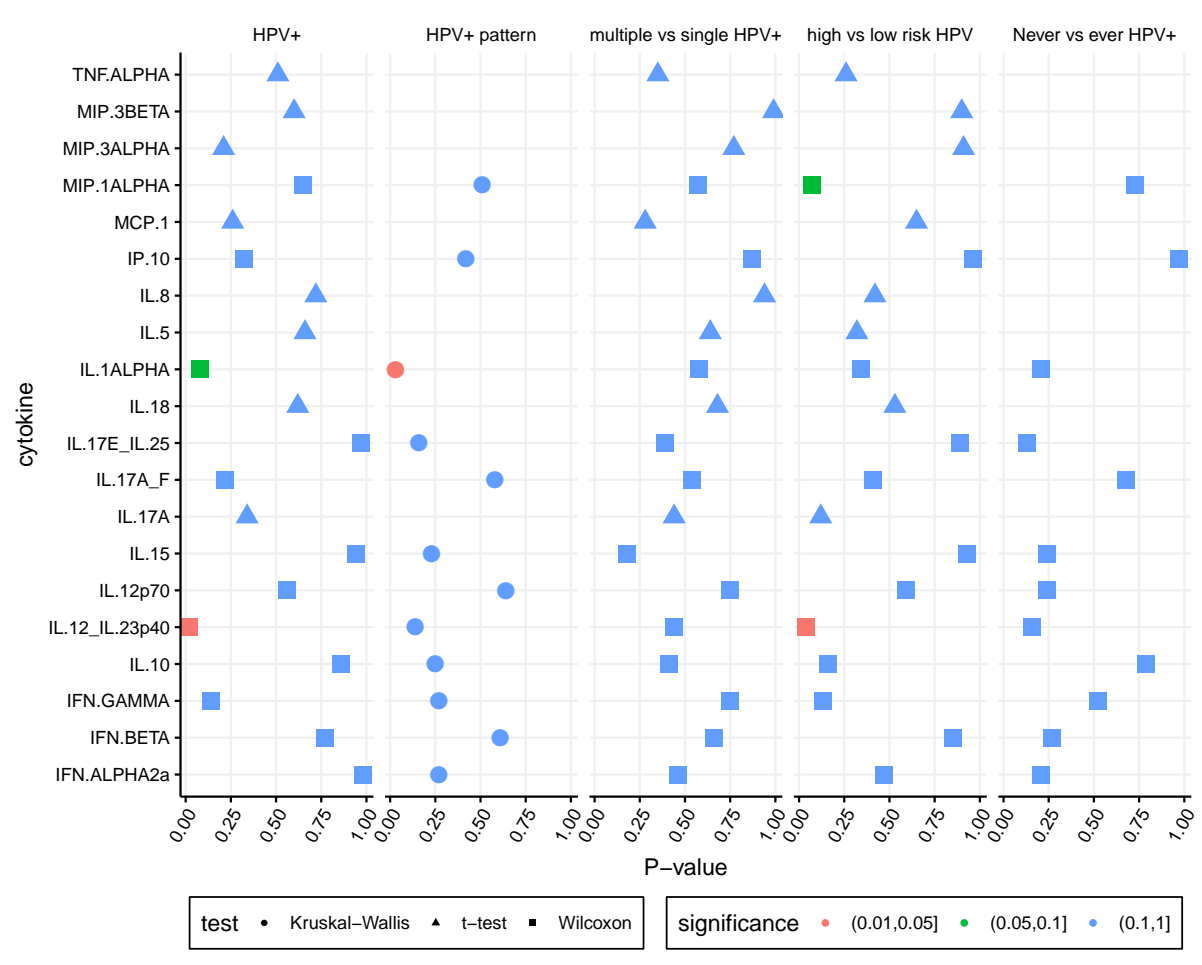


Supplementary Figure 4: Number of linear models with at least one statistically significant covariate, with normally (turquoise) and not normally (red) distributed residuals depending on the number of covariates in each model.

\section{Parsimony of linear models}

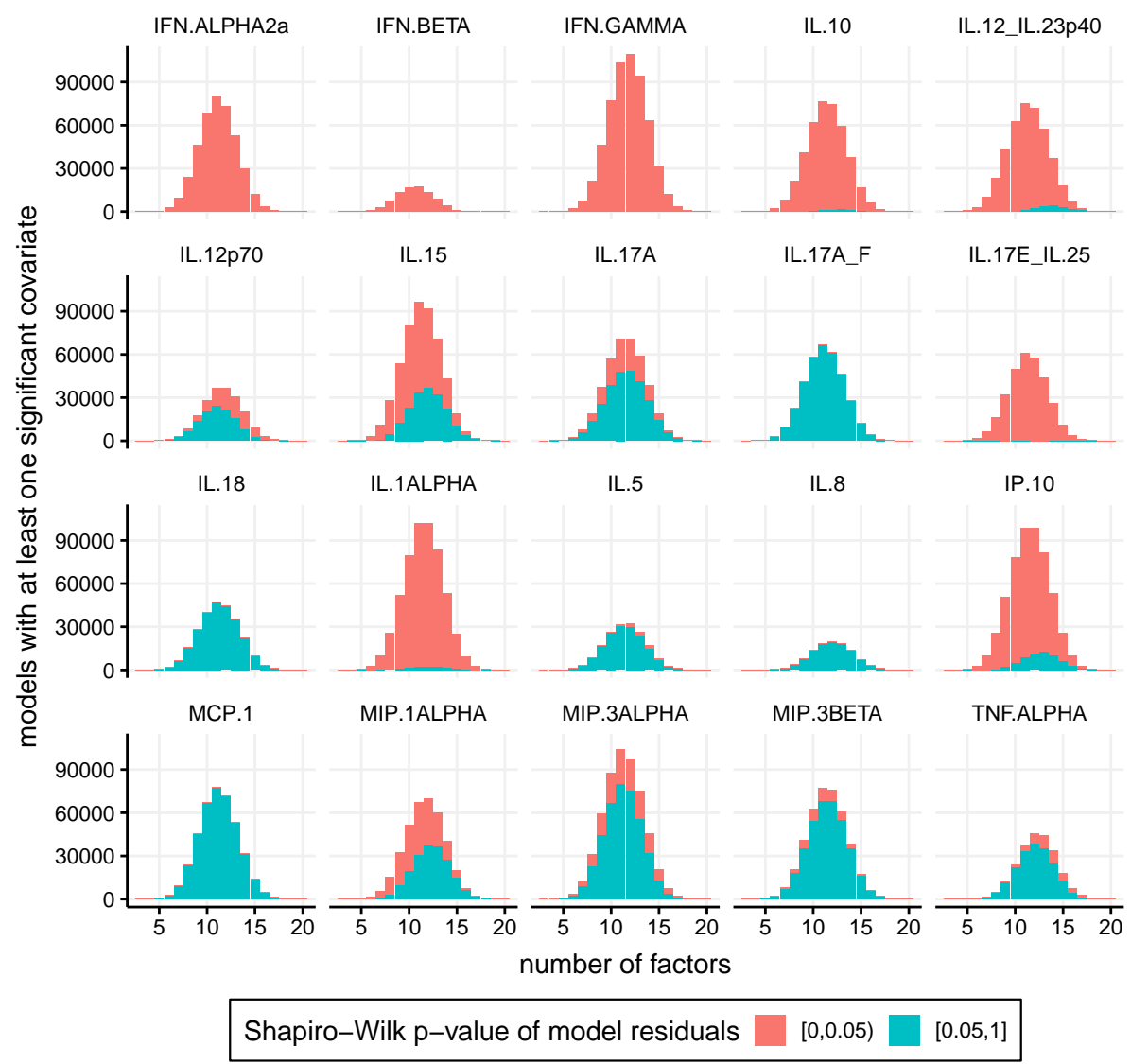

